option after failure of medical treatment in certain patients for whom a surgical intervention is prohibitive. Postprocedural pneumonia is a possible complication and should be watched for in postprocedure care.

\section{References}

1. Hagan JL, Hardy JD. Lung abscess revisited. A survey of 184 cases. Ann Surg. 1983;197:755-62.
2. Wali SO. An update on the drainage of pyogenic lung abscesses. Ann Thorac Med 2012;7:3-7.

3. Herth F, Ernst A, Becker HD. Endoscopic drainage of lung abscesses: technique and outcome. Chest. 2005;127:1378-81

4. Schmitt GS, Ohar JM, Kanter KR, Naunheim KS. Indwelling transbronchial catheter drainage of pulmonary abscess. Ann Thorac Surg. 1988;45: 43-7.

5. Shlomi D, Kramer MR, Fuks L, Peled N, Shitrit D. Endobronchial drainage of lung abscess: the use of laser. Scand J Infect Dis. 2010;42:65-8.

\title{
Chest wall reconstruction after resection of a chest wall sarcoma by osteosynthesis with the titanium MatrixRIB (Synthes) system
}

\author{
L. Marleen Boerma, MD, ${ }^{\mathrm{a}}$ Mike Bemelman, MD, ${ }^{\mathrm{b}}$ and Thijs van Dalen, MD, PhD, ${ }^{\mathrm{a}}$ Utrecht, \\ The Netherlands
}

Solid tumors of the chest wall are rare, with soft-tissue sarcomas being the predominant primary malignancy. Wide local excision is the standard operative treatment for soft-tissue sarcomas, but obtaining adequate margins by removal of the tumor en bloc with adjacent ribs results in large defects of the thoracic cage. Today, chest wall resections can be performed with acceptable morbidity and mortality. ${ }^{1}$

Various methods for chest wall reconstruction have been described. The best method should provide stability of the chest, watertight and airtight closure, and acceptable cosmetic appearance. Ideally, it would also be a relative easy procedure. Marlex (Chevron Phillips Chemical Company LP, The Woodlands, Tex) mesh, acrylic cement, polytetrafluoroethylene (Gore-Tex; WL Gore \& Associates, Inc, Flagstaff, Ariz) patches, bone cement, fascia grafts, and silicone implants, alone or in combination, have all been described for this purpose. ${ }^{2}$ All work reasonably well, although none of these solutions fulfill all the described requirements.

Recently, 2 patients underwent a chest wall resection for a soft-tissue sarcoma. In both cases, the chest wall was reconstructed with titanium MatrixRIB system (Synthes $\mathrm{GmbH}$, Zuchwil, Switzerland) plates to bridge the gap between the costal ends.

\footnotetext{
From the Department of Surgery, ${ }^{\mathrm{a}}$ Diakonessenhuis, Utrecht, The Netherlands; and the Department of Surgery, ${ }^{\mathrm{b}}$ University Medical Center, Utrecht, The Netherlands. Disclosures: Authors have nothing to disclose with regard to commercial support. MatrixRIB is a trademark of Synthes GmbH, Zuchwil, Switzerland. L.M.B. and M.B. contributed equally to this article.

Received for publication Jan 3, 2013; revisions received April 27, 2013; accepted for publication May 9, 2013; available ahead of print July 15, 2013.

Address for reprints: Thijs van Dalen, $\mathrm{MD}, \mathrm{PhD}$, Bosboomstraat 1, $3582 \mathrm{KE}$ Utrecht,

The Netherlands (E-mail: tvdalen@diakhuis.nl).

J Thorac Cardiovasc Surg 2013;146:e37-40

$0022-5223 / \$ 36.00$

Copyright (c) 2013 by The American Association for Thoracic Surgery

http://dx.doi.org/10.1016/j.jtcvs.2013.05.010
}

\section{CLINICAL SUMMARIES \\ Patient 1}

A 65-year-old male patient presented with a mass on the trunk. On examination, there was a firm swelling on the right lower dorsolateral aspect of the thorax, fixed on the chest wall. Computed tomographic and magnetic resonance imaging (MRI) scans showed a solid tumor measuring $7 \times 4 \times 6 \mathrm{~cm}$, with paravertebral involvement of ribs 9 , 10, and 11 (Figure 1). Incisional biopsy revealed a softtissue sarcoma, histomorphologically classified as a leiomyosarcoma (grade 2). A resection was done en bloc, with the overlying part of the latissimus dorsi muscle and the involved and adjacent ribs 8 through 11 . The resulting defect was closed with 4 titanium rib plates (MatrixRIB system) to bridge the defects in the respective ribs. The plates were each fixed to the transected ribs with 4 screws



FIGURE 1. Computed tomographic scan shows a $7.2 \times 4.4 \times 6.2 \mathrm{~cm}$ neoplasm in the right dorsal chest wall, with ingrowth in the intercostal space. 




FIGURE 2. Macroscopic picture of the attachment of the titanium rib plates.

on either costal end. In addition, the remaining superior part of the lastissimus dorsi muscle was detached from its dorsal insertion and its proximal origin. The vascularized latissimus dorsi flap was used as the inner lining of the reconstruction and approximated to the bony delineation of the defect and the titanium plates (Figure 2).

The patient was extubated immediately after the operation. Apart from mild seroma formation, his postoperative course was uneventful. Seven days after the operation, the patient was discharged. At a relatively short follow-up of

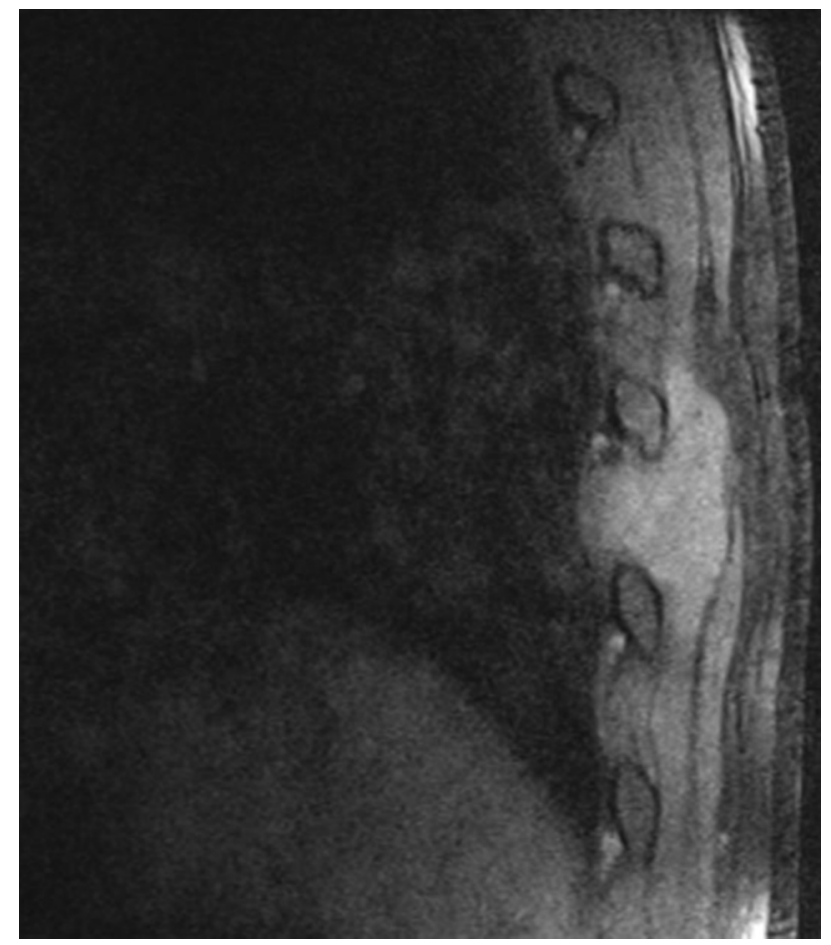

FIGURE 3. Magnetic resonance imaging shows a sarcoma in the back muscles and left lower chest wall. There is ingrowth in the subpleural space.
3 months, the pulmonary function was good, and there was no visible deformity.

\section{Patient 2}

A 28-year-old male patient presented with a slowly growing mass beneath the left scapula. On examination, the tumor was seen to be fixed to the dorsal chest wall. Additional MRI scan showed a 5-cm tumor in the erector spinae with intercostal invasion between ribs 7 and 8, approximately 1 to $2 \mathrm{~cm}$ lateral of the costotranversal joints (Figure 3). A core needle biopsy showed a low-grade soft-tissue sarcoma, histomorphologically classified as an angiomatoid fibrous histiocytoma. A resection of the sarcoma was done en bloc with the overlying latissimus dorsi muscle and by transecting ribs 7 and 8 laterally and by disarticulating both ribs posteromedially. Reconstruction of the defect was done with Dualmesh (Gore) to close the pleural defect. Rib reconstruction was then performed with 2 titanium plates bridging the rib defects. The plates were each medially attached to the transverse processes with 2 screws and laterally to the transected rib end using 3 screws (Figure 4). The patient was immediately extubated at the end of the operation. His postoperative course was uncomplicated. Seventeen days after the operation, the patient was discharged. During follow-up, there appears to have been some loss of contour as a result of the missing back muscles; however, there are no functional deficits.

\section{DISCUSSION}

In these 2 patients, titanium rib plates were used to repair a chest wall defect after sarcoma resection. Reconstruction was easy to perform, resulted in a stable fixation of the chest wall, and was free of cosmetic deformities.

Stabilization of the chest wall with a prosthesis is considered necessary after major resections to decrease the need for prolonged mechanical ventilation and to improve postoperative pulmonary function. ${ }^{3}$ Historically, various 

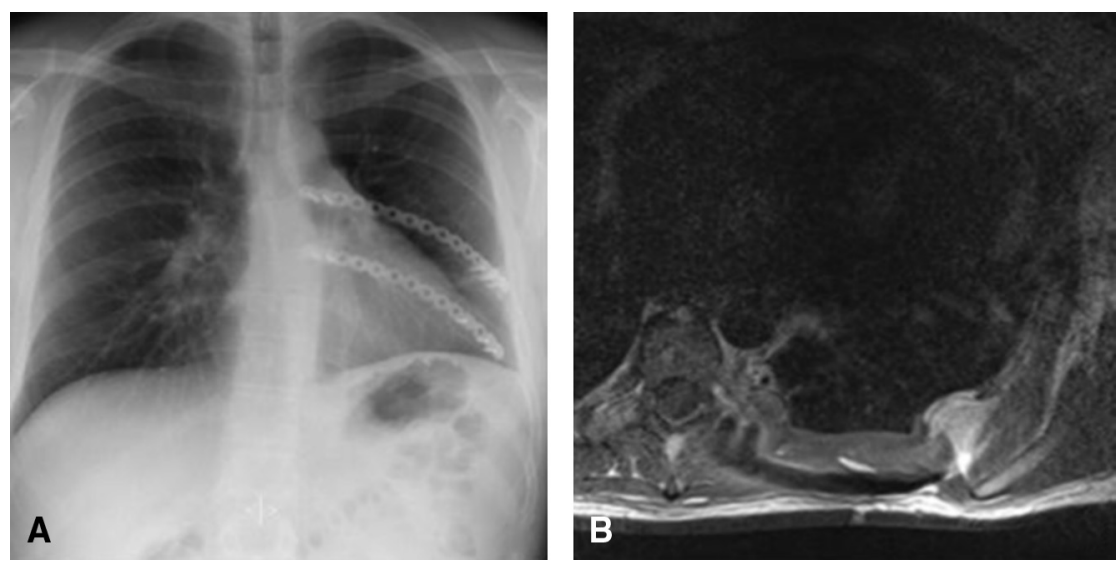

FIGURE 4. Thoracic radiography (A) and magnetic resonance imaging (B) show status after excision of the soft-tissue sarcoma in the left posterior chest wall with rib prostheses at costae 7 and 8 . The nonferromagnetic material causes little interference on computed tomography and magnetic resonance imaging.

therapeutic options have been described for this purpose, such as Marlex mesh, acrylic cement, polytetrafluoroethylene (Gore-Tex) patches, bone cement, fascia grafts, and silicone implants, alone or in various combinations. ${ }^{2}$ An adequate prosthesis requires rigidity to abolish paradoxic chest motion, an inert nature to allow ingrowth of fibrous tissue and decrease the likelihood of infection, malleability to allow it to be fashioned to the appropriate shape at the time of the operation, radiolucency to allow radiographic follow-up of the underlying problem, and, ideally, technical ease of performance. ${ }^{2}$ None of the previously mentioned methods of reconstruction fulfill all these criteria.

Originally, titanium rib plates were used in trauma surgery to reconstruct fractured ribs to allow better respiratory recovery. For the same reason, these strong yet flexible plates were used to stabilize the thoracic cage in the patients described here. The use of titanium rib plates has several advantages. These plates allow individual rib continuity to be maintained and may allow physiologically appropriate "bucket handle" rib movements better than larger fixed prosthesis. The plates are designed in such a manner that they mimic the elasticity of the average rib, thus providing exceptional dynamics and comfort. ${ }^{4}$ Relative to other materials, titanium has a high strength-to-weight ratio, and its osteointegration is better than stainless steel. In addition, the nonferromagnetic material has low density and causes little interference on computed tomographic and MRI scans, which improves the quality of these imaging modalities when used during follow-up (Figure 4). ${ }^{5}$ Furthermore, in the hands of an experienced trauma surgeon, use of these plates is a fairly easy and rapid method for internal fixation of the ribs. A relative drawback is that the surgeon must be familiar with the basic osteosynthesis principles in general and with the MatrixRIB system in particular. Fixation demands exact contouring of the titanium plates to fix them flush on the remaining rib. The drilling and screwing also need some specific knowledge.
First, it is crucial to press the plate flush onto the remaining rib and keep it there, with the provided clamps, while drilling and screwing; this ensures a correct drill and screw length and thus an optimal stable construct. Inserting the screws is a rather delicate procedure; the screw heads have a fine design and are susceptible to stripping if one does not recognize this. A minimum of 3 screws on either side is recommended, but experience shows that 2 screws may be sufficient.

A hypothetical problem in the future may be the breakage of the plates. It is a well-known principle in orthopedics that if bone healing does not take over the function of osteosynthesis material, all materials will eventually break, even titanium plates. In both patients described here, bone healing is not possible because the ribs have been removed completely, and thus eventual plate breakage is to be expected. We anticipate, however, that such breakage probably will have no clinical consequence because the plates will by that time be encapsulated by scar tissue. In a hypothetical worst-case scenario, a symptomatic broken plate should be removed. We expect the removal of such a plate would be minor relative to the initial operation.

Either a synthetic mesh or a muscular flap can be used to mimic the parietal pleura and complete the inner layer of the chest wall reconstruction. The latter may be preferable as a means of avoiding or decreasing the risk of infection, obliterating spaces, and covering the synthetic mesh.

\section{CONCLUSIONS}

In conclusion, these cases demonstrate the potential use of titanium rib plates for reconstructing chest wall defects. The described method comes close to fulfilling all the requirements of an ideal reconstruction technique. It is stable, it allows physiologically natural rib movements, it has acceptable cosmetic appearance, it causes little 
interference on computed tomography and MRI when used during follow-up, and it is easy to perform. Combined with a mesh or muscular flap, it provides both airtight and watertight closure of the chest wall.

\section{References \\ 1. Mansour KA, Thourani VH, Losken A, Reeves JG, Miller JI Jr, Carlson GW, et al. Chest wall resections and reconstruction: a 25-year experience. Ann Thorac Surg. 2002;73:1720-5; discussion 1725-6.}

2. Khalil el-SA, El-Zohairy MA, Bukhari M. Reconstruction of large full thickness chest wall defects following resection of malignant tumors. J Egypt Natl Canc Inst. 2010;22:19-27.

3. Lardinois D, Müller M, Furrer M, Banic A, Gugger M, Krueger T, et al. Functional assessment of chest wall integrity after methylmethacrylate reconstruction. Ann Thorac Surg. 2000;69:919-23.

4. Bottlang M, Helzel I, Long WB, Madey S. Anatomically Contoured Plates for Fixation of Rib Fractures. J Trauma. 2010;68:611-5.

5. Coonar AS, Qureshi N, Smith I, Wells FC, Reisberg E, Wihlm JM. A novel titanium rib bridge system for chest wall reconstruction. Ann Thorac Surg. 2009;87:e46-8.

\title{
Transapical aortic valve (JenaValve) implantation for severe aortic insufficiency and aortic aneurysm
}

\author{
Friederike Schlingloff, MD, Christian Frerker, MD, Ulrich Schäfer, MD, and Ralf Bader, MD, Hamburg, \\ Germany
}

Transapical transcatheter aortic valve implantation has become a valid treatment option for severe aortic stenosis in patients who are at high risk or are not operative candidates. ${ }^{1}$ Various self-expanding (CoreValve; Medtronic Inc, Minneapolis, Minn) or balloon-inflatable (Sapien XT; Edwards Inc, Irvine, California) valves are currently widely used. Recently, transcatheter aortic valve implantation has also been used to treat pure aortic regurgitation. ${ }^{2}$ Several cases in which the CoreValve has successfully been used have been reported. ${ }^{3,4}$ Because conventional transcatheter aortic valve implantation prostheses usually need calcification of the native valve for anchoring, however, their use is limited and not free of device embolization. The JenaValve (JenaValve Technology GmbH, Munich, Germany) is a self-expandable valve with 3 metal feelers that allows anatomically correct positioning within the native valve and can be used in a transapical approach. The probe elements are placed into the native cusps, and the valve is then clipped onto the leaflets with a "paper clip" mechanism and released from the catheter. No rapid-pacing is needed, because the valve is instantly fully functional. The JenaValve does not need calcification of the native valve for anchoring of the prosthesis and thus seems well suited for the use in pure aortic regurgitation.

From the Asklepios Klinik St Georg, Hamburg, Germany.

Disclosures: Authors have nothing to disclose with regard to commercial support. JenaValve is a trademark of JenaValve Technology GmbH, Munich, Germany.

Received for publication April 11, 2013; revisions received May 14, 2013; accepted for publication May 23, 2013; available ahead of print July 15, 2013.

Address for reprints: Friederike Schlingloff, MD, Department of Cardiac Surgery, Asklepios Klinik St Georg, Lohmühlenstrasse 5, 20099 Hamburg, Germany (E-mail: f.schlingloff@asklepios.com).

J Thorac Cardiovasc Surg 2013;146:e40-1

$0022-5223 / \$ 36.00$

Copyright (c) 2013 by The American Association for Thoracic Surgery

http://dx.doi.org/10.1016/j.jtcvs.2013.05.029
Its value in treating aortic stenosis has been shown in recent publications. ${ }^{5}$ Treatment of aortic regurgitation in combination with aortic aneurysm usually warrants aortic root replacement, however, with aortic valve replacement as a conventional open procedure. We report a case of the successful use of the transapical JenaValve as an off-label approach in a patient with pure aortic insufficiency and aortic aneurysm.

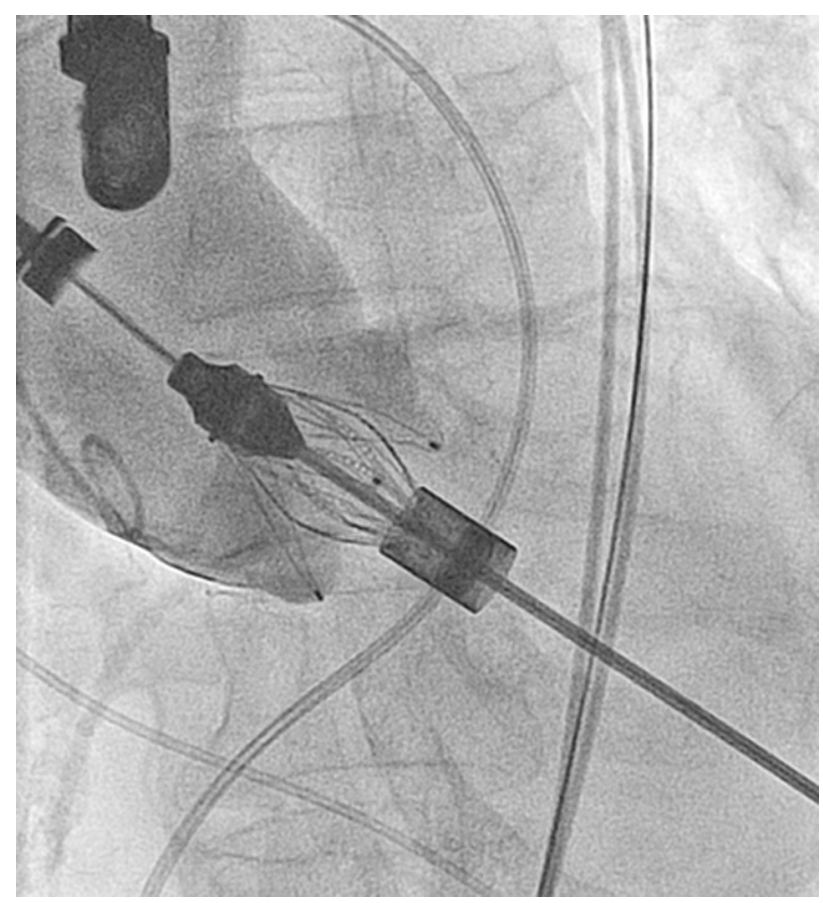

FIGURE 1. After the valve was directly inserted into the annulus, the feelers were exposed and positioned at the base of the aortic cusps with fluoroscopic confirmation. 